\title{
Pornografía no consentida: alternativas en el ordenamiento jurídico de la propiedad intelectual de Estados Unidos
}

$* * * *$

\author{
Fredrick Vega-Lozada \\ Universidad Interamericana de Puerto Rico \\ fvega@intermetro.edu
}

Recibido: 1 de noviembre de 2020

Aceptado: 4 de diciembre de 2020

\section{Resumen}

La pornografía no consentida es un acto de violencia en la que atentan contra la dignidad, reputación y honor de las personas. En esta investigación se presentan algunas de las alternativas jurídicas existentes para enfrentar estos actos de violencia con el derecho de la propiedad intelectual, específicamente con el derecho de autor. Esta investigación se basa en el ordenamiento jurídico de Estados Unidos de Norteamérica, en la que se analizó la Ley de Derecho de Autor de 1976, la Ley de No Robo Electrónico de 1997, La Ley de Decencia de las Comunicaciones de 1996, La ley de Privacidad Electrónica en las Comunicaciones de 1986, la ley de Derechos de Autor en el Milenio Digital de 1998 y las excepciones y aclaraciones que presenta la jurisprudencia. La investigación concluye que hay alternativas disponibles para las víctimas de estos actos de pornografía no consentida. Sin embargo, para hacer más accesible a las víctimas los remedios del derecho de autor norteamericano, se recomienda enmendar algunas de las leyes vigentes analizadas.

Palabras clave: pornografía no consentida, Ley de Derechos de Autor de 1978, Ley de Decencia de las Comunicaciones de 1996, Ley de Derechos de Autor en el Milenio Digital de 1998.

\section{Non-Consensual Pornography: United States of America Intellectual Property Law Alternatives}

\footnotetext{
Abstract

Non-consensual pornography is an act of violence that undermines the dignity, reputation and honor of people. This research presents some of the existing legal alternatives to face these acts
} 
of violence with intellectual property law, specifically with copyright. This research is based on the legal system of the United States of America, the United States Copyright Law of 1976, the Electronic Non-Theft Act of 1997, The Communication Decency Law of 1996, The Electronic Communications Privacy Act of 1986, the Digital Millennium Copyright Act of 1998 and the exceptions and clarifications presented by the jurisprudence. The investigation concludes that there are alternatives available to victims of these acts of non-consensual pornography. However, to make North American copyright remedies accessible to victims, it is recommended to amend some of the current Acts analyzed.

Key words: Non-consensual pornography, United States Copyright Law of 1976, the Electronic Non-Theft Act of 1997, The Communication Decency Law of 1996, The Electronic Communications Privacy Act of 1986, the Digital Millennium Copyright Act of 1998.

\section{Pornografia não autorizada: alternativas no sistema jurídico de propriedade intelectual dos Estados Unidos}

\section{Resumo}

A pornografia não consensual é um ato de violência que mina a dignidade, a reputação e a honra das pessoas. Esta pesquisa apresenta algumas das alternativas jurídicas existentes para enfrentar esses atos de violência com a lei de propriedade intelectual, especificamente com direitos autorais. Esta pesquisa é baseada no sistema jurídico dos Estados Unidos da América, a lei de direitos autorais de 1976, a Lei de Não-Roubo Eletrônico de 1997, a Lei de Decência de Comunicação de 1996, a Lei de Privacidade Eletrônica no Comunicaçóes de 1986, a Lei de Direitos Autorais no Milênio Digital de 1998 e as exceçóes e esclarecimentos apresentados pela jurisprudência. A investigaçáo conclui que existem alternativas disponíveis para as vítimas desses atos de pornografia não consensual. No entanto, para tornar os recursos de direitos autorais americanos mais acessíveis às vítimas, recomenda-se alterar algumas das leis atuais analisadas.

Palavras chave: pornografia não consensual, lei de direitos autorais de 1976, Lei de Não-Roubo Eletrônico de 1997, Lei de Decência de Comunicação de 1996, Lei de Privacidade Eletrônica no Comunicaçóes de 1986, aLei de Direitos Autorais no Milênio Digital de 1998.

\section{Introducción}

La violencia de género es uno de los vestigios más denigrantes y despectivos de la raza humana (Expósito y Moya, 2011). ${ }^{1}$ Sin embargo, la violencia de género especialmente contra las mujeres tiene un nuevo impulso con el uso de las nuevas tecnologías de comunicaciones electrónicas (Puente, Romero y Cupeiro, 2015; Rico, 1996) y es algo que continúa en aumento. El propósito de esta investiga-

1 En 1942, la Carta de las Naciones Unidas menciona expresamente los derechos humanos en siete lugares de su texto. El quinto considerando dice claramente "que los pueblos de las Naciones 
ción es realizar un análisis jurídico sobre algunas respuestas del derecho de la propiedad intelectual existentes en los Estados Unidos (en adelante, EE. UU.) que pudieran apoyar los esfuerzos para hacer frente a este atentado contra la dignidad del ser humano (De Oliveira y Taroco, 2020) relacionado a lo que se conoce como "la pornografía no consentida".

\section{La pornografía no consentida}

Podemos definir a la pornografía no consentida como la divulgación o amenazas de divulgación de imágenes o videos sexualmente explícitos de una persona sin su consentimiento (Citron y Franks, 2014; Franks, 2015). Usualmente acontece después de la disolución de una relación de pareja, como una forma de controlar a la víctima o "castigar" a esa expareja. (Burris, 2014; Stroud, 2014). Originalmente, se usó el término "porno venganza", pero este no reconoce la naturaleza abusiva sexual de este acto (Maddocks, 2018). Otro término usado en la literatura de Reino Unido, Nueva Zelanda y Australia es el "abuso sexual basado en imágenes" (McGlynn y Rackley, 2017) y "la difusión no consensual de imágenes íntimas" (Maddocks, 2018). Si bien la pornografía no consentida, no es un fenómeno nuevo, en los últimos años ha aumentado exponencialmente (McGlynn y Rackley, 2017; Uhl et al., 2018). Existen muchos portales de internet dedicados al negocio de la pornografía que están completamente dedicados a alojar y facilitar la pornografía no consentida (Uhl et al., 2018). Hay estudios que concluyen que las víctimas de estos actos tienen efectos permanentes en su salud mental (Cecil, 2014; Citron y Franks 2014, Kopf, 2013). ${ }^{2}$

Este acto de pornografía no consentida es la pesadilla de miles de personas en el mundo, que sufren debido a despechos de su expareja que, sin permiso, divulga

Unidas han reafirmado en la Carta su fe en los derechos fundamentales del hombre, en la dignidad y el valor de la persona humana y en la igualdad de derechos de hombres y mujeres, y se han declarado resueltos a promover el progreso social y a elevar el nivel de vida dentro de un concepto más amplio de la libertad". La Declaración sobre la Eliminación de la Violencia contra la Mujer de la Asamblea General de las Naciones Unidas define como "violencia de género": "Todo acto de violencia basado en la pertenencia al sexo femenino que tenga o pueda tener como resultado un daño o sufrimiento físico, sexual o psicológico para la mujer, inclusive las amenazas o tales actos, la coacción o privación arbitraria, tanto si se producen en la vida pública o privada”.

2 En diciembre de 2015, la investigadora Paula Vargas de Brea, del Centro de Estudios de Libertad de Expresión y Acceso a la Información adscrito a la Universidad de Palermo, había publicado una definición básica abarcadora, en la que expresaba que la pornografía no consentida era la publicación o puesta a disposición, o la manera de hacerlo al público en general o de terceros en particular, de forma deliberada, utilizando internet u otra tecnología de 
sus imágenes en poses eróticas, sexuales o situaciones sexuales. ${ }^{3}$ La mayoría de las víctimas son mujeres ${ }^{4}$ y otros grupos vulnerables, como la comunidad LGTBQ+ (Vaina, 2019). La pornografía no consentida es una dura lección que se sufre con sorpresa, dolor y lágrimas alrededor del mundo (Rood y Schriner, 2020). No hay país exento (Musoni, 2019) de casos en donde se vulnera la privacidad de una persona. ${ }^{5}$ Algunas personas han expresado en sus reclamaciones legales que "es la denigración total" (Goldstein, 2020).

Los victimarios, al realizar estos actos, tienen varias intenciones, tales como: causarle daño a la imagen de la persona o a la reputación "de una expareja (y/o a su pareja actual)" o lucrar con las imágenes o videos. El Reino Unido fue primer país que comenzó la discusión legal sobre el tema (End Violence Against Women, 2013), cuando hombres comenzaron a publicar en distintos portales pornográficos videos o fotos de sus exparejas mujeres. ${ }^{6}$ Luego, esta conducta se diseminó ${ }^{7}$ en EE. UU. y otros países.

la comunicación de imagen/es, o audio/s o contenidos/os audiovisuales de naturaleza sexual explicita sin el consentimiento de la víctima por parte de un individuo con el que esta había mantenido una relación íntima (De Brea, 2015). Véanse las definiciones del Código Penal Argentino en su artículo 155. Otro punto de vista similar: Vega-Lozada (2014, pp. 53-72).

3 Portales tales como: www.myex.com, ugotposted.com, Is Anyone Up y otros.

4 El Parlamento japonés dictó una norma específica contra el porno de la venganza a fines de 2014. En el primer mes desde la entrada en vigor de la ley, la Policía registró 110 sitios. La mayoría de las víctimas tenía menos de 30 años y, en más de la mitad de los casos, la distribución de fotografías o videos de desnudos o con carácter sexual fue obra de parejas o exparejas de los afectados; 99 de los 110 casos fueron mujeres (Matsui, 2015).

5 "It is not difficult to look at naked women on the Internet. There are, after all, a lot of men and women who post nude photos of themselves online hoping for page views, extra income, or just exhibitionist titillation. So with the news over the weekend of "leaked" nude photos of various celebrities, can we please all agree not to search these pictures out? If we want to look at nude people, let's restrict ourselves to photos of people who actually want us to see them nude. It's not like there's a lack of them to choose from. Because, look: When people seek out stolen images like the ones just released of Jennifer Lawrence, Kate Upton, and other celebrities, those people are violating these women in much the same way that the person who stole the pictures did. There's a reason why the public tends to revel in hacked or stolen nude pictures. It's because they were taken without consent. Because the women in them (and it's almost always women who are humiliated this way) did not want those shots to be shared" (Valenti, 2014).

6 En el mundo contemporáneo, la explotación de las imágenes de artistas y celebridades es indudablemente un gran negocio, que se utiliza constantemente en los mercados lucrativos de publicidad (Schechter y Thomas, 2003, pp. 263-269).

7 Hay otras conductas en las telecomunicaciones que atentan contra la dignidad del ser humano (Huber, 2020). 


\section{Preguntas de investigación}

Las preguntas que orientaron la siguiente investigación son:

a) ¿La Ley de Derechos de Autor de EE. UU. le ofrece algún remedio a las víctimas de la pornografía no consentida?

b) ¿En EE. UU. cuál es la responsabilidad de los proveedores de servicios de internet?

c) ¿La persona o sujeto víctima de la pornografía no consentida tiene alguna protección o defensa en el derecho de la propiedad intelectual?

En esta investigación presentaremos alternativas jurídicas disponibles en el derecho de la propiedad intelectual y derecho de autor de E.E. U.U. y, en este contexto, es que analizaremos el ordenamiento jurídico norteamericano vigente.

Lamentablemente, en los portales de internet existe una demanda de imágenes de pornografía no consentida, habiendo muchos factores que la promueven (McGlynn et al., 2020).

Algunos de los problemas para investigar y adjudicar esto actos son probatorios. Por ejemplo, la imagen podría haber sido tomada sin el conocimiento de la víctima, apropiada ilegalmente o realizada con el victimario.

Además, los portales de internet no revelan la información para identificar a las personas o a los usuarios. Para la identificación de los victimarios, hay que utilizar mecanismos especiales de descubrimiento de prueba. Los tribunales de EE. UU. requieren que los demandantes identifiquen a todas las partes antes del descubrimiento de prueba, aunque existen unas excepciones a esas reglas de procedimiento civil donde se puede obligar a los proveedores de servicios informáticos a revelar información de sus usuarios. Sin lugar a dudas, la victima de pornografía no consentida en EE. UU. tiene un arduo camino para ejercer sus derechos.

A continuación, examinaremos algunas de las alternativas jurídicas relacionadas con la primera pregunta de investigación.

\section{Ley de Derechos de Autor de EE. UU. de 1976}

La Constitución de los Estados Unidos le otorgó al Congreso el poder de crear una ley de derechos de autor bajo el artículo 1 , sección 8 , cláusula 8 , conocida como la Cláusula de Derechos de Autor (Fenning, 1929). La Ley de Derechos de Autor de ese país es una ley principalmente patrimonial (Donner, 1992) que dispone de protecciones de derechos de autor al creador de cualquier obra original que "se fija en cualquier medio de expresión tangible." La ley le otorga derechos exclusivos al propietario. También el autor de una obra inédita generalmente se 
reserva el derecho de decidir si la publica o permite su visualización y, por consiguiente, a elegir destruir sus obras en caso de que decida que no son aptas para el público. La ley dispone de amplios remedios por cualquier infracción a cualquiera de sus disposiciones. Los creadores de las obras registradas tienen derecho a daños reales y/o estatutarios. Las imágenes pornográficas están investidas con la protección de derechos de autor al ser creadas y fijadas en medios tangibles de expresión, ${ }^{8}$ por lo que la Ley de Derechos de Autor es un remedio para las víctimas de pornografía no consentida.

Con respecto al tema de la autoría, si bien es obvia para los autorretratos o selfies, el análisis de la autoría al amparo de la legislación norteamericana vigente se vuelve más complicado para las fotografías tomadas por otros. Cuando la persona no toma la fotografía, hay dos posibilidades. Primero, la persona que es víctima conoce a la persona que toma la fotografía y participa en su creación. Segundo, la persona que es víctima no es consciente y la fotografía se toma de forma no consentida. En el derecho de autor norteamericano el primer asunto es relativamente fácil de adjudicar, sin embargo, el segundo es complicado. Las fotografías de índole sexual tomadas por un miembro de una pareja como parte de la vida sexual de esa pareja pueden considerarse como obras conjuntas. La Ley de Derechos de Autor de EE. UU., en su artículo 101, define un "trabajo o creación en conjunto" como "una creación o trabajo preparado por dos o más autores con la intención de que sus contribuciones se fusionen". El Tribunal de Apelaciones del Noveno Circuito en el caso Brod v. General Pub. Group (2002) ${ }^{9}$ establece los factores a considerar para adjudicar la autoría a una imagen fotográfica. El Tribunal explica en su fallo que una imagen fotográfica en conjunto es aquella en la que el autor controla la obra y es "la mente inventiva o maestra quien crea o da efecto a la idea", si los "coautores hacen la obra en partes inseparables o interdependientes de un todo unitario".

En la pornografía no consentida, las víctimas no tenían la intención de vender o poner a disposición del público la obra, que, en este caso, es la imagen. Como

8 Transmisión en audio digital: la Ley de Derechos de Autor permite la reproducción de la obra en copias o registros, preparar obras derivadas basadas en la obra original, distribuir al público copias o registros grabados de la obra a través de su venta, alquiler o préstamo, exhibir públicamente la obra registrada, en el caso de obras literarias, obras musicales, películas y otras obras audiovisuales, hacer pública la obra mediante la publicación o exhibición al público de obras como libros, gráficas, esculturas y otros, y finalmente el autor puede hacer pública la obra por medio de la transmisión en audio digital en el caso de canciones u otros tipos de grabaciones de audio (Ley de Derechos de Autor de EE. UU., 17 U.S.C. artículos 102(1), 102(3), 102(4), 102(5), 102(6) у 103).

9 Brod v. General Pub. Group, Inc., 32 Fed. Appx. 231 (9th Cir. 2002). 
explicamos, el artículo 106(3) otorga al autor de una obra el derecho de "distribuir copias [...] de la obra por venta u otra transferencia”. Por lo cual, la víctima de la pornografía no consentida tiene todo el derecho a reclamar la imagen obtenida de esta forma y presentar una reclamación por violación al derecho de autor.

$\mathrm{Al}$ aplicar este fallo, podemos deducir que cuando hay una grabación sin el conocimiento o consentimiento de la víctima, o cuando se graba una sesión de intimidad o desnudo con una cámara conectada a internet sin el conocimiento de la persona que está siendo grabada, la persona que ejerce el control primario del trabajo es la persona que está siendo grabada. Por lo menos, esa persona debe ser vista como un autor en conjunto. Obviamente, los Tribunales tendrían que tomar esta determinación al aquilatar la prueba y los hechos de caso a caso. La víctima de una publicación de pornografía no consentida en coautoría disfruta de todos los derechos por su imagen. Es una violación a la Ley de Derecho de Autor norteamericano la publicación de imágenes en coautoría. El Tribunal también señala que "el control en muchos casos será el factor más importante para adjudicar el derecho de propiedad sobre la obra" que, en este caso, son las imágenes.

La Ley de Derechos de Autor de EE. UU. dispone de un marco legal que permite a los autores registrados presentar reclamaciones de daños y perjuicios contra infractores a esta ley. El registro no es una condición para la protección del derecho de autor, pero solo obras registradas pueden tener una protección completa que incluye los llamados "daños y perjuicios estatutarios". Esta protección se aplica a los daños y perjuicios estatutarios cuando la obra se registra, o si se registra 90 días después de que se infringe o viola la ley, o un mes después de que el titular de los derechos de autor tenga conocimiento de la infracción a la ley. La Ley de Derechos de Autor de EE. UU. define "daños reales" como la suma de los daños sufridos por el propietario de los derechos de autor y "cualquier beneficio del infractor que sea como consecuencia de la infracción".

La adjudicación de los daños depende de la prueba desfilada en el Tribunal, pero serán "no menor de $\$ 750$ o mayor de $\$ 30,000$ " a menos que "la infracción se realice de manera deliberada". Si el Tribunal, en el descubrimiento de prueba, considera que la infracción fue deliberada, tiene la discreción de aplicar lo que se conoce como los "daños estatutarios", los cuales son punitivos. Estos serán de una suma no mayor a "150.000 dólares" por obra infringida. Dado que muchos de estos casos de pornografía no consentida implican una imagen, la determinación del Tribunal de lo que es "justo" "dependerá de la prueba presentada. ${ }^{10}$

1017 U.S.C. $\$ 504($ b) (2010). 46 Id. $\$ 504(c)(1),(2)$. 


\begin{tabular}{|c|c|c|c|}
\hline Imagen & $\begin{array}{l}\text { Expresiones de los } \\
\text { tribunales }\end{array}$ & $\begin{array}{l}\text { Artículos de la Ley } \\
\text { de Derechos de Au- } \\
\text { tor norteamericana }\end{array}$ & $\begin{array}{c}\text { Jurisprudencia } \\
\text { (casos) }\end{array}$ \\
\hline $\begin{array}{l}\text { Autorretratos o } \\
\text { selfies }\end{array}$ & $\begin{array}{l}\text { Como regla general, } \\
\text { el autor es la parte } \\
\text { que realmente crea } \\
\text { la obra, es decir, la } \\
\text { persona que traduce } \\
\text { una idea en una } \\
\text { expresión fija y tan- } \\
\text { gible con derecho a } \\
\text { la protección de los } \\
\text { derechos de autor. }\end{array}$ & 102 & $\begin{array}{l}\text { Naruto v. Slater, } \\
\text { No. 16-15469, } 2018 \\
\text { WL 1902414 (9th } \\
\text { Cir. Apr. 23, 2018); } \\
\text { Cmty. for Creative } \\
\text { Non-Violence v. } \\
\text { Reid, } 490 \text { U.S. 730, } \\
737 \text { (1989); Con- } \\
\text { sumer Prod. Safety } \\
\text { Comm'n v. GTE Syl- } \\
\text { vania, Inc., } 447 \text { U.S. } \\
\text { 102, } 108 \text { (1980) }\end{array}$ \\
\hline $\begin{array}{l}\text { Trabajo o creación } \\
\text { en conjunto }\end{array}$ & $\begin{array}{l}\text { Un autor supervisa } \\
\text { el trabajo ejerciendo } \\
\text { control. Probable- } \\
\text { mente, sea una } \\
\text { persona que haya } \\
\text { formado la imagen } \\
\text { al colocar a las per- } \\
\text { sonas en su posición } \\
\text { y organizar el lugar } \\
\text { donde estas deben } \\
\text { estar. }\end{array}$ & 101 & $\begin{array}{l}\text { Aalmuhammed v. } \\
\text { Lee, } 202 \text { F.3d 1227, } \\
1234 \text { (9th Cir. 2000) }\end{array}$ \\
\hline
\end{tabular}

Tabla 1. Resumen de alternativas al amparo de la Ley de Derechos de Autor. Fuente: elaboración propia.

Además, el Congreso aprobó la Ley de No Robo Electrónico (en adelante, NET, por sus siglas en inglés), ${ }^{11}$ que dispone la presentación de cargos criminales para aquellas personas que continúen infringiendo la Ley de Derechos de Autor. La Ley NET tipifica como delito la infracción deliberada de la Ley de Derechos de Autor cuando el valor total de la obra infringida supera la cuantía de $\$ 1.000$ en el mercado (Brown, 1998).

11 United States No Electronic Theft Act (NET Act) de 1997, Pub. L. 105-147, Stat. 2678, que enmienda el código 17 U.S.C. \$\$ 101, 506, 507; 18 U.S.C. 2319, 2320; 28 U.S.C. 1498. Dispone para el enjuiciamiento penal de las personas que participan en infracción de derechos de autor de EE. UU. aunque no haya ningún beneficio económico o comercial por la infracción. Las sanciones máximas pueden ser de cinco años de prisión, además de multas. 
Esto puede ser un disuasivo para reducir la incidencia en la diseminación de imágenes de pornografía no consentida. Reiteramos que estos remedios, al amparo de la la Ley de Derechos de Autor, son para las obras registradas (Goldman, 2003).

Es difícil que una víctima de la pornografía no consentida registre su imagen íntima. También los procesos de registro y de litigación son largos y, generalmente, la víctima no quiere exponerse a estos procesos judiciales públicos. Además, usualmente, las víctimas no tienen los recursos económicos para contratar a un abogado especializado en derechos de autor ${ }^{12}$ y la Ley de Derechos de Autor no aborda el tema de eliminación de las imágenes en los portales de internet. Concluimos que esta ley provee remedios a una víctima de la pornografía no consentida. Específicamente, provee protección cuando las imágenes sean autofotos o cuando la víctima sea la autora o coautora de la imagen. Asimismo, existe una limitación a la protección que otorga la ley, la cual es en relación con los costos de las reclamaciones judiciales.

Existe un asunto distinto que es presentar las reclamaciones contra los portales de internet que violan Ley de Derechos de Autor norteamericana.

\section{Reclamaciones al amparo del derecho de la propiedad intelectual contra los portales de internet involucrados en la pornografía no consentida en EE. UU.}

\subsection{La Ley de Decencia de la Comunicación de $1996^{13}$}

El Estado de derecho en EE. UU. permite que la persona perjudicada, además de presentar una causa de acción contra el victimario, también pueda presentar una causa de acción en contra del portal de internet que, por negligencia, publica imágenes que violan los derechos de autor.

Sin embargo, existen varios escollos jurídicos para lograr exitosamente una reclamación de esta índole. Es difícil prevalecer contra aquellos portales de internet, proveedores de servicio de internet o sus operarios que promocionan o son huésped o aquellos cuyo negocio principal se nutre de las imágenes de la pornografía no consentida (Tomeo, 2010). El más importante es la existencia del artículo 230 del Título V de la Ley de Telecomunicaciones de $1996^{14}$ (en ade-

12 También, el presentar un interdicto al amparo de la legislación norteamericana para procurar la expedición de una orden de cese y desista cuesta un promedio de \$2.000.

1347 U.S.C. Sections 230.

14 Comúnmente conocida como la Ley de Decencia en las Comunicaciones y su artículo 230. 
lante, CDA, artículo 230). La política pública de esta ley dispone los siguientes objetivos (Pedro, 1996; Luño, 1998):

(1) promover el desarrollo continuo de la Internet y otros servicios informáticos interactivos y otros medios interactivos; (2) para preservar el libre mercado dinámico y competitivo que existe actualmente para la Internet y otros servicios informáticos interactivos, libre de regulación estatal o norteamericano; (3) fomentar el desarrollo de tecnologías que maximizan el control del usuario sobre la información que es recibida por los individuos, familias y escuelas que utilizan el internet y otros servicios informáticos interactivos; (4) para eliminar los desincentivos para el desarrollo y la utilización de bloqueo y filtrado de tecnologías que permiten a los padres restringir el acceso de sus hijos en línea a material objetable o inapropiado; y (5) para garantizar la observancia estricta de las leyes penales norteamericanas y sancionar la trata de obscenidad, acoso y el acoso por medio de la computadora. ${ }^{15}$

Específicamente, el artículo 230 tiene como objetivo asegurar que los proveedores y usuarios de "servicios de informática" no estén expuestos a la responsabilidad como "editores de contenido" de cualquier información proporcionada por otro "proveedor de información de contenido". ${ }^{16}$ Asimismo, dispone que "ningún proveedor o usuario de un servicio informático interactivo será tratado como el editor o representante de cualquier información proporcionada por otro proveedor de contenido de la información." ${ }^{17}$

La ley define "servicio informático interactivo" como

cualquier servicio de información, sistema o proveedor de software de acceso que proporciona o permita acceso a una computadora por varios usuarios a un servidor de la computadora, incluyendo específicamente un servicio o sistema que proporciona acceso a Internet y tales sistemas operados o servicios ofrecidos por las bibliotecas o centros de enseńanza. ${ }^{18}$

"Proveedor de contenido de la información" se define como "cualquier persona o entidad que es responsable, en todo o en parte, por la creación o el desarrollo

1547 U.S.C. 230 (b).

16 H. R. Rep. No 105-775 inciso I (E).

1747 U.S.C. 230 (c) (1).

1847 U.S.C. 230 (f) (2). 
de la información proporcionada a través de Internet o cualquier otro medio”. ${ }^{19}$ Entonces, quiere decir que bajo las inmunidades dispuestas por esta ley de 1996, los proveedores de servicios o portales de internet no son responsables civilmente por lo que expongan y divulguen, solamente responderá el tercero, quien hizo la expresión (Montero, 2000; Plaza, 2001) o, como en estos casos de pornografía no consentida, las imágenes. ${ }^{20}$ Sin embargo, la ley dispone de excepciones importantes para apoderar a las víctimas de la pornografía no consentida a fin de que puedan reclamar exitosamente contra las empresas proveedoras de servicios de internet, incluidas las redes sociales. Estas excepciones son las siguientes.

\subsection{Excepciones a la inmunidad del artículo 230 y el campo ocupado}

El Estatuto norteamericano establece que "no se interpretará en menoscabo del cumplimiento" de alguna de las leyes penales norteamericanas o "para limitar o ampliar cualquier legislación relacionada a la propiedad intelectual”. ${ }^{21}$ Esta excepción relacionada con la propiedad intelectual, específicamente con el derecho de autor norteamericano, es muy importante en términos de la pornografía no consentida, porque ¿a quién le pertenece el derecho de autor de las imágenes o sonido que se envía a un portal de internet? Ya hemos previamente analizado esta situación cuando se publican sin consentimiento expreso los autorretratos y las imágenes en conjunto. El acto de publicarlas derrumbaría la inmunidad del artículo 230. Además, este artículo promueve el cumplimiento de cualquier ley

1947 U.S.C. 230 (f) (3).

20 Zeran v. America Online, Inc. 129 F. 3d 327, 330 (4th Cir. 1997). El Tribunal de Apelaciones del Cuarto Circuito evaluó la dirección y alcance de la de inmunidad de la Sección 230. El Tribunal de Apelaciones señaló que en la promulgación de la Sección 230 "Congress recognized the threat that tort-based lawsuits post to freedom of speech in the new and burgeoning Internet médium" y el propósito de "encourage service providers to self-regulate the dissemination of offensive material over their services" (Zeran, 129 F.3d pp. 330-331). La decisión de Zeran otorgó inmunidad a un proveedor de servicio de Internet en cualquier reclamación que surja de los contenidos de terceros. Véase, tambien, Green v. America Online, 318 F.3d 465, 470-71 (3d Cir. 2003); Batzel v. Smith, 333 F.3d 1018, 1031 n. 18 (9th Cir. 2003); Carafano v. Metrosplash.com Inc., 339 F.3d 1119, 1122 (9th Cir. 2003); Ben Ezra, Weinstein \& Co. v. America Online Inc., 206 F.3d 980, 984-86 (10th Cir. 2000); En Doe v. MySpace, 474 F. Supp. 2 d 843, 848 (WD Tex 2007). La mayoría de los Tribunales en EE. UU. aplican Zeran y el CDA articulo 230 (c) (1) siempre que los proveedores de internet se abstengan de la filtración o de censurar la información en sus portales. Véase Almeida v. Amazon.com, Inc., 456 F.3d 1316, 1322 n.3 (Cir. 11 de 2006).

2147 U.S.C. 230 (e) (1) y (2). 
estatal coherente con "la aplicación de la Ley de Privacidad de Comunicaciones Electrónicas de 1986 (Communications Privacy Act, en adelante, ECPA) ${ }^{22}$ de $1986^{23}$ o cualquiera de las modificaciones introducidas por dicha ley ${ }^{24}$ o cualquier ley estatal similar" ${ }^{25}$

Es importante destacar la prohibición a la divulgación que trae la ley de ECPA de $1986^{26}$ en cuanto a prohibir la divulgación, "prohibits the intentional or willful interception, accession, disclosure, or use of one's electronic communication”. Otra excepción vital poco comentada es que las imágenes que se toman y se transmiten a la pareja para su uso y satisfacción no pueden ser interceptadas o sustraídas y divulgadas posteriormente a terceros sin el consentimiento de la entonces expareja. ${ }^{27}$ Existen varios casos sobre la ley ECPA aplicados precisamente a

22 "(1) No effect on criminal law.

Nothing in this section shall be construed to impair the enforcement of section 223 or 231 of this title, chapter 71 (relating to obscenity) or 110 (relating to sexual exploitation of children) of title 18, or any other Federal criminal statute.(2) No effect on intellectual property law Nothing in this section shall be construed to limit or expand any law pertaining to intellectual property.(3) State law Nothing in this section shall be construed to prevent any State from enforcing any State law that is consistent with this section. No cause of action may be brought and no liability may be imposed under any State or local law that is inconsistent with this section. (4) No effect on communications privacy law nothing in this section shall be construed to limit the application of the Electronic Communications Privacy Act of 1986 or any of the amendments made by such Act, or any similar State law".

23 "The ECPA defines [the term] 'electronic communication' as any transfer of signs, signals, writing, images, sound, data, or intelligence of any nature transmitted in whole or in part by wire, radio, electromagnetic, photoelectric, or photocell system that affects interstate commerce”. Las redes sociales, los portales, blogs y correo electrónico están protegidos por esta ley: "the legislative history clearly shows Congress' intent to include it within the definition of 'electronic communications"'.

24 La Ley Electronic Communications Privacy Act de 1986 (ECPA). (18 U.S.C. \$ 2701-11) "prohibits the intentional or willful interception, accession, disclosure, or use of one's electronic communication".

2547 U.S.C. SECTION 230 (e) (3) y (4).

2618 U.S.C. $\$ 2701-11$.

27 Además de estar ante un acto que constituye una violación a la intimidad, honor y reputación de la persona-vicitma perjudicada. Por ejemplo, en el caso de Robbins v. Lower Merion School District (2010), conocido como el caso de los WebcamGate, dos escuelas públicas repartieron a estudiantes menores de edad, para fines académicos, unas computadoras $\mathrm{u}$ ordenadores portátiles. Se probó que ambas escuelas superiores violaron las disposiciones de ECPA al activar remotamente en las computadoras portátiles unos programas espías para monitorear el uso académico de las computadoras portátiles. El 23 de febrero de 2010 se estipularon los daños por cerca de \$610.000 In the Matter of Lower Merion School District, 
accesos ilegales por medios electrónicos (LaMotte, 2020), ${ }^{28}$ pero esta ley dispone para la protección para los que interceptan comunicaciones y extraen las fotos de manera ilegal. Otro artículo que no es comentado es el llamado del "buen samaritano".

\subsection{El buen samaritano: la violación a la relación contractual como causa próxima del daño}

En las relaciones contractuales en internet permea la proliferación de la impunidad de las conductas relacionadas con la pornografía no consentida, y es que en todos los portales y redes sociales hay contratos de uso explícitos. ${ }^{29}$ Por lo tanto, ¿qué ocurre cuando yo le aviso a una red social que me han llevado mis fotos o que han construido con mis fotos un perfil ficticio e inexistente y que en este perfil se están publicando fotos trabajadas o cambiadas por una aplicación común como Photoshop, en la que la publicación de esta imagen mancilla mi integridad? Ya sabemos que la red social está exenta de responsabilidad por la artículo CDA 230, pero, a su vez, la misma ley -en su artículo 230, inciso (c) (2)le otorga protección a ese portal de internet cuando actúe para evitar violaciones a la Ley de Derechos de Autor. Ese es el artículo que se conoce como el "buen samaritano", cuando hay una expresión en la ley que a su mejor entendido:

c) Protection for "Good Samaritan" blocking and screening of offensive material

(1) Treatment of publisher or speaker

No provider or user of an interactive computer service shall be treated as the publisher or speaker of any information provided by another information content provider.

(2) Civil liability No provider or user of an interactive computer service shall be held liable on account of-

(A) any action voluntarily taken in good faith to restrict access to or availability of material that the provider or user considers to be obscene, lewd, lascivious, filthy,

Appellant, v. Blake J. Robbins, Hanson Court de 9 de marzo de 2012. Barnes v. Yahoo!, Inc., 2005 WL 3005602, (D. Or. 2005) este es el caso emblemático sobre el tema.

28 La Comisión Federal de Comercio (FTC) modificó sus reglamentos de tal manera que ahora se exige que el programador de la aplicación reciba la autorización del padre o representante para recabar los datos de cualquier menor de 13 años de edad. Esto incluye información de los datos del teléfono móvil, el número telefónico o la ubicación geográfica del dispositivo. Cómo proteger la privacidad de su hijo en internet.

29 Doe v. MySpace, 528 F.3d 413 (5th Cir. 2008). 
excessively violent, harassing, or otherwise objectionable, whether such material is constitutionally protected; or

(B) any action taken to enable or make available to information content providers or others the technical means to restrict access to material described in paragraph (1).

Por lo tanto, una víctima de actos de pornografía no consentida puede advertirle al blog, red social o portal de internet la violación a las leyes de derecho de autor, y si ese portal no hace nada sabiendo que está inmune por estos incisos de la ley, su inacción constituye una violación del contrato de servicio.

$\mathrm{El}$ incumplimiento contractual tiene consecuencias de un acto negligente y culposo. Además, este incumplimiento contractual es la causa próxima del daño por la infracción al derecho a la propiedad intelectual de la víctima. Fíjese que el estatuto norteamericano protege al proveedor de servicio de internet o red social de alguna reclamación por ejercer estos incisos del artículo del buen samaritano. Es una alternativa legal débil y se debe probar caso a caso, debido a que hay que comprobar que los servicios de internet específicamente crean y fomentan el contenido de los portales de pornografía no consentida. Ahora bien, si el portal de internet es simplemente un conducto pasivo para la actividad ilegal, es poco probable que los Tribunales consideren al demandado un proveedor de contenido de información bajo el artículo 230.

\subsection{La gran excepción: Fair Housing Council of San Fernando Valley v. Roommates.com, LLC $^{30}$}

Este es uno de los casos más estudiados y criticados en los EE. UU. La empresa Roommates.com, LLC hizo un portal de internet para desarrollar perfiles de usuarios que buscaban vivienda. Una vez diseńado el perfil, ese programa buscaba coincidencias entre esos usuarios y arrendadores o vendedores de vivienda. ${ }^{31}$ Este portal, al momento del litigio, contaba con aproximadamente 150.000 anuncios activos y recibía alrededor de un millón de visitas al día. Roommates.com trató de aprovecharse de la recaudación de ingresos producto de anunciantes y suscriptores con pago. Los suscriptores podrían buscar los listados de viviendas o publicar oportunidades de vivienda en el portal y crear también un perfil. ${ }^{32} \mathrm{El}$ portal hizo

30489 F.3d 921 (9th Cir. 2007), revisado en parte en 521 F.3d 1157 (9th Cir. 2008).

31 Véase: http://www.roomates.com/.

32 En ese proceso, el programa obligaba a los usuarios a responder una serie de preguntas que, además de solicitar información básica como el nombre, la ubicación y dirección de correo electrónico, le requirió en aquellas fechas a cada suscriptor revelar su sexo, orientación sexual 
unos algoritmos activos que categorizaban a sus usuarios, pero tenían una base de instrucciones que violaban la ley federal norteamericana de vivienda. El Tribunal de Apelaciones del Noveno Circuito de EE. UU. decidió que la creación de algoritmos que categoricen, analicen y sugieran respuestas se consideraría "creador de contenidos". ${ }^{33}$ Además, un portal de internet que "contribuye materialmente" al presunto acto de ilegalidad pierde la inmunidad. El Tribunal hizo hincapié en la distinción entre "publicar" contenido de un tercero y realmente crear el contenido. Por lo tanto, si un demandado es el proveedor de contenido de información, la inmunidad del artículo 230 no se aplica. Un proveedor de servicios informáticos puede ser simultáneamente un "editor y creador" de material "proporcionado por otro proveedor de contenido de información". Si el portal simplemente proporciona un foro o "conducto neutral" para que el material sea comunicado, entonces no será un proveedor de contenido de información según el artículo 230 (Ambale, 2008). Sin embargo, los tribunales pueden considerar al demandado como "responsable" de la "creación o desarrollo" de la información cuando examine la prueba y encuentre que el portal participó activamente en la expresión.

y si tenía niños o iba a tener o a llevar niños a la vivienda.

Cada suscriptor debía describir sus preferencias de compañeros de piso con respecto a los mismos tres criterios: el sexo, la orientación sexual y si tenían niños. El portal también promovía que los suscriptores proporcionasen "comentarios adicionales" para que describieran qué tipo de vecino le gustaría tener en su vivienda. Se le asignaba un seudónimo y toda esta información se divulgada a través del portal. Los usuarios elegían entre dos niveles de servicio: Los que utilizaban el nivel de servicio gratuito del portal podían crear su propia página de perfil, buscar los perfiles de otros y enviar mensajes de correo electrónico personales. También recibían correos electrónicos periódicos de la plataforma de Roommates.com, que informaba de oportunidades de vivienda disponibles que coincidieran con sus preferencias. Los suscriptores que pagaban una cuota mensual también obtenían la capacidad de leer mensajes de correo electrónico de otros usuarios y veían los comentarios adicionales de otros suscriptores. La parte demandante, Fair Housing Council of San Fernando Valley, alegó que el negocio de Roommates.com violó la ley norteamericano Fair Housing Act (FHA) y otras leyes de vivienda de California.

33 "Roommate's connection to the discriminatory filtering process is direct and palpable: Roommate designed its search and email systems to limit the listings available to subscribers based on sex, sexual orientation and presence of children. Roommate selected the criteria used to hide listings, and Councils allege that the act of hiding certain listings is itself unlawful under the Fair Housing Act, which prohibits brokers from steering clients in accordance with discriminatory $1170^{*} 1170$ preferences. We need not decide the merits of Councils' claim to hold that Roommate is sufficiently involved with the design and operation of the search and email systems -which are engineered to limit access to housing on the basis of the protected characteristics elicited by the registration process - so as to forfeit any immunity to which it was otherwise entitled under section 230 ”. 
También, un portal de internet puede ser señalado como creador de contenido si "fomenta [d] específicamente la creación del contenido ilegal. El fallo del caso Sarah Jones v. Dirty World Entertainment Recordings LLC (2014) ${ }^{34}$ no aceptó el fomento de contenido ilegal como una determinación para derrumbar la inmunidad del CDA 230. En este caso, los demandantes -un profesor de secundaria, Jones, y una porrista de los Cincinnati Bengals- demandaron al portal thedirty.com y a su operador por difamación por una serie de calumnias. La parte demandada presentó una moción de sentencia sumaria con el argumento de que el articulo $230^{35}$ le brindaba inmunidad de responsabilidad por el contenido creado por terceros. El Tribunal de distrito denegó la moción y el caso fue a juicio dos veces. El Tribunal de Distrito determinó en su fallo que el artículo 230(c) (1) solo se aplica en la medida en que un proveedor de servicios informáticos interactivos como Dirty World no tenga derecho a la protección de las reclamaciones basadas en la publicación de información si el demandado es responsable, en todo o en parte, por la creación o el desarrollo de la información. El Tribunal de Distrito, al evaluar la prueba, concluyó que el propietario de un portal que promueve intencionalmente publicaciones ilegales es enjuiciable por las publicaciones de terceros. Si el portal ańade sus propios comentarios o si adopta los mensajes, entonces se convierte en un "creador" de contenido $y$, por ende, no tiene derecho a la inmunidad. El fallo del Tribunal de Distrito determinó "[d]efendants, when they re-published the matters in evidence, had the same duties and liabilities for re-publishing libelous material as the author of such materials". ${ }^{36}$

El Tribunal de Apelaciones en el Sexto Circuito revocó el fallo del Tribunal de Distrito y adoptó el criterio o test de la "contribución material":

[W]e interprets the term "development" as referring not merely to augmenting the content generally, but to materially contributing to its alleged unlawfulness. In other words, a website helps to develop unlawful content, and thus falls within the exception to section 230, if it contributes materially to the alleged illegality of the conduct.

$\mathrm{Al}$ analizar esta decisión, podemos concluir que si un portal ayuda a desarro-

34 No. 13-5946 (6th Cir. June 16, 2014).

35 Ley de Decencia en las Comunicaciones, 47 U.S.C. $\$ 230$ (c) (1).

36 Sarah Jones v. Dirty World Entertainment Recordings LLC, 766 F. Supp.2d 828, 836 (E.D. Kentucky 2011). 
llar contenidos ilegales, pierde la protección del artículo 230 de CDA. Si el portal contribuye materialmente a la ilegalidad del contenido, entonces será responsable de ese contenido ilegal que aparece en su portal ${ }^{37}$ (Lichter, 2013).

\section{Inmunidad adicional el proveedor de servicios de internet y el puerto seguro ${ }^{38}$}

En el 1998, el Congreso de EE. UU. aprobó la Ley de Derechos de Autor en el Milenio Digital (Digital Millenium Copyright Act, en adelante, DMCA), la cual añadió el artículo 512 de la Ley de Derecho de Autor norteamericano. ${ }^{39}$ La ley redujo y ajustó la responsabilidad civil de los propietarios de derechos de autor $y$ proveedores de servicios de internet ${ }^{40}$ a fin de colocar la carga sobre la identificación de la infracción de derecho de autor precisamente en la persona afectada por la infracción y no en los proveedores de servicio de internet que fueran solo mere conduit de terceras personas que utilizan sus servicios de proveedores de comunicaciones. ${ }^{41}$

El artículo 512 no define la conducta que hace responsable a los proveedores

37 En un caso que se tranzó extrajudicialmente, Hare v. Richie, 2012 WL 3773116 (D. Md. August 29, 2012). En este portal, bajo el control de Dirty World, se hicieron unos comentarios difamatorios en contra de Hare, los hechos apuntaron a que Dirty World se convirtió en proveedor de contenido y perdía la inmunidad del CDA 230.

38 EE. UU. inició en 1999 negociaciones con la Unión Europea para conseguir una declaración de adecuación del nivel de protección de datos personales. La protección de la intimidad y de los datos en este país se enmarca en un entramado de regulación sectorial, tanto a nivel federal como estatal, que se combina con la autorregulación industrial. A fin de superar los problemas derivados de esta dispersión normativa, el Departamento de Comercio de los EE. UU. presentó como documento para la discusión entre las autoridades norteamericanas y de la Unión Europea un borrador de "principios de puerto seguro", a fin de garantizar a los operadores que se adhirieran a estos una "presunción de adecuación" al nivel de protección exigido por la Directiva, permitiéndose así la libre transferencia internacional de datos a dichos operadores. El Acuerdo de "Puerto Seguro" constó de siete principios básicos, referidos a la notificación (información a los afectados), opción (posibilidad de oposición de los afectados), transferencia ulterior a terceras empresas, seguridad, integridad de los datos (principios de finalidad y proporcionalidad), derecho de acceso y aplicación, fue invalidado el 6 de octubre de 2015 por la Corte Europea de Justicia en la decisión del caso C-362/14 Maximillian Schrems v. Data Protection Commissioner.

3917 U.S.C. $\$$ 512. Pub. L. 105-304, 112 Stat. 2860.

40 Sen. Rep. No. $105-190$ p. 8.

41 Subsecciones 512(c)(3), 17 U.S.C. $\$$ 512(c)(3), 512(f), 17 U.S.C. $\$$ 512(f), 512(g) y 17 U.S.C. $\$ 512(\mathrm{~g})$. 
de servicio de internet de una infracción directa, contributaria o vicaria, ${ }^{42}$ pero identifica varias actividades que puede realizar un proveedor de servicios de internet para inmunizarlos contra reclamaciones y dispone de remedios extraordinarios. ${ }^{43}$ El artículo 512 dispone de lo que se llama "cuatro puertos seguros", que otorgan las siguientes inmunidades: ${ }^{44}$ las comunicaciones transitorias de redes digitales, el almacenamiento en el sistema memoria corta o temporal, la información de los usuarios que se almacena temporalmente en los sistemas o redes y las herramientas de búsqueda de información

Cada uno de estos puertos seguros representa un aspecto particular en la operación normal de internet, por lo que aborda un aspecto diferente en las posibles infracciones de derechos de autor norteamericano. ${ }^{45} \mathrm{El}$ inciso (l) del artículo dispone que los puertos seguros no tienen por objeto enumerar todas las defensas que tiene un proveedor de servicios de internet que infringe los derechos de autor, incluso cumpliendo con las disposiciones de puerto seguro (Jie, 2011). Los beneficios de este artículo son: la inmunidad de reclamaciones legales y los remedios extraordinarios disponibles, exceptuando el inciso (j) del artículo cuando hay una infracción por un asunto cubierto por el puerto seguro. ${ }^{46} \mathrm{El}$ artículo reconoce que es importante que un tribunal norteamericano tenga la facultad para ordenar que un proveedor de servicios de internet ayude a detener una infracción del derecho de autor. El alcance de la ayuda y apoyo a reducir una violación a los derechos de autor está limitado por el inciso (j) cuando un proveedor de servicios está actuando como una mere conduit de las comunicaciones de otros y cumple con todos los requisitos del inciso (a) del artículo. El Tribunal tiene la facultad para otorgar remedios provisionales, como interdictos para impedir al proveedor de servicios de internet el proveer acceso a un suscriptor o titular de una cuenta que usa el servicio del proveedor de internet para violar la ley de derechos de autor. También la orden permite que el proveedor de servicios de internet le ponga fin a la cuenta de los suscriptores en el extranjero. Finalmente, la ley provee para solicitarle al tribunal una orden que le impida al

42 Perfect 10, Inc. v. Giganews, Inc.; Flynn v. Siren-BookStrand, Inc., 2013 WL 5315959 (20 de septiembre de 2013). El caso presenta un problema interesante en relación con el derecho de una parte de enviar una notificación de eliminación de la DMCA.

43 A esto se llama "Puerto Seguro", Rossi v. Motion Picture Ass'n of Am., 391 F.3d 1000 (9th Cir. 2004); ALS Scan, Inc. v. RemarQ Cmtys., Inc., 239 F.3d 619 (4th Cir. 2001).

4417 U.S.C. $\$ 512(1)$ Section 107, 17 U.S.C. $\$ \$ 107-122$

45 Textile Secrets Intl'l, Inc. v. Ya-Ya Brand, Inc., 524 F.Supp.2d 1184 (C.D.Cal.2007).

46 Flynn v. Siren-BookStrand, Inc., 2013 WL 5315959 (Sept. 20, 2013); Xcèntric Ventures, LLC v. Mediolex Ltd., 2012 WL 5269403 (D.Ariz Oct 24, 2012). 
proveedor de servicios de internet proporcionarles acceso a infractores de la ley de derechos de autor. ${ }^{47}$ Para todos los demás puertos seguros están disponibles otros remedios extraordinarios. ${ }^{48}$

\subsection{Procedimientos de notificación, aviso de retiro voluntario y/o eliminación (note-and-takedown)}

Es un procedimiento expedito extrajudicial para que el dueño de un derecho de autor evite el tener que acudir a los tribunales para obtener un remedio provisional y reivindicar un derecho de autor o de marcas infringido. Esto es una alternativa costo-efectiva (Wang, 2018). Si la imagen que infringe el derecho de autor está disponible en internet, hay que impedir y bloquear al acceso del público a esta para impedir que puedan realizarse copias adicionales ilegales en otras direcciones de internet. Incluso, un interdicto provisional urgente para bloquear estas acciones puede tomar demasiado tiempo. ${ }^{49}$ Por esta razón, el Congreso norteamericano instituyó un sistema de notificación y retiro "voluntario" ${ }^{50}$ para, rápidamente, eliminar cualquier infracción de derechos de autor. ${ }^{51}$ El sistema de notificación y retiro comienza cuando un proveedor de servicios designa a un agente para recibir estas notificaciones. ${ }^{52}$ El Registro de Derechos de Autor norteamericano mantiene un directorio de agentes disponibles para el público y así apoyar el retiro voluntario. ${ }^{53} \mathrm{~A}$ su vez, se requiere

$47 \quad 17$ U.S.C. $\$ 512(\mathrm{j})(1)(\mathrm{B})$.

4817 U.S.C. $\$ 512(\mathrm{j})(2)$.

49 "The safe harbor provision of the DMCA states that a 'service provider shall not be liable for monetary relief' if all of the following requirements are met:

(1) it does not have actual knowledge that the material on its network is infringing;

(2) it is not aware of facts or circumstances that would make the infringing activity apparent; and

(3) upon obtaining knowledge or awareness of such infringing activity, it acts expeditiously to remove or disable access to the copyrighted material" Xcentric Ventures, LLC $v$. Mediolex Ltd., 2012 WL 5269403 (D.Ariz. October 24, 2012)

50 Tal vez menos voluntario, debido a que un proveedor de servicios tiene que participar en ella con el fin de aprovechar todos los puertos seguros a excepción del de "mera transmisión".

51 Design Furnishings, Inc. v. Zen Path LLC, No. 10-2765, 2010 WL 4321568 (E.D. Cal. October 21, 2010).

52 Las limitaciones de responsabilidad dispuestas aplican a un proveedor de servicio de internet si este designó a un agente para recibir notificaciones de infracciones, poniendo a su disposición, a través de su portal en la web, una ubicación accesible al público y proporcionando a la Oficina Norteamericano de Derecho de Auto Norteamericano.

53 Se puede requerir el pago de un canon por parte de los proveedores de servicios de internet para cubrir los gastos de mantenimiento del directorio. 
que la declaración incluya "que la información en la notificación es exacta" y "que la parte reclamante está autorizada para actuar en nombre del propietario del derecho de autor que presuntamente se ha infringido". La segunda parte de este requisito debe hacerse "bajo pena de perjurio". Es una notificación de interacción que tiene una fuerza y un peso enormes sobre quien la notifica. El artículo 512 (f) dispone de la responsabilidad civil de declaraciones falsas. ${ }^{54}$

Una vez que un proveedor de servicios de internet quiera acogerse a los puertos seguros, ${ }^{55}$ sabe que su sistema debe eliminar con rapidez o bloquear el acceso al material presuntamente infractor de derechos de autor norteamericano. Ese conocimiento puede venir de una notificación adecuada del propietario del derecho de autor o cuando el proveedor de servicios de internet tiene conocimiento de hechos o circunstancias para determinar que se violan los derechos de autor. Un proveedor de servicios de internet tiene que ser proactivo y tener un sistema ágil y eficiente para resolver de manera razonable una notificación de acuerdo a este artículo de la ley. Asimismo, no puede simplemente ignorar un aviso o notificación de infracción que cumpla con lo dispuesto. Debe intentar rápidamente ponerse en contacto con la persona que hizo la notificación o tomar medidas razonables para ayudar a que la recepción de la notificación cumpla con todas las disposiciones de las protecciones del artículo 512 del DMCA. Esto es adecuado para las víctimas de pornografía no consentida, porque no necesitan registrar sus derechos de autor o contratar a un abogado para presentar un aviso de "descolgar" la imagen del portal de internet. Las víctimas solo necesitan presentar su nombre, firma, identificar la imagen y proporcionar enlaces al material que consideren que infringe sus derechos de autor. También tienen que presentar la información de contacto y verificación por escrito de que consideran que el uso del material no está autorizado. Sin embargo, es usual que las víctimas descubran que sus imágenes se vuelven a publicar en otros portales de pornografía. Los portales de internet de pornografía son focos de contenido pirateado e infractor

54 Bajo esta sección, cualquier persona que falsifique materialmente a sabiendas de que: (1) el material o actividad infringe, o (2) el material o la actividad se borró o se desactivó por error de identificación será responsable por los daños y perjuicios, incluidos los gastos y honorarios de abogados, incurridos por el presunto infractor, por cualquier dueño de los derechos de autor o por un proveedor de servicios que reciba un daño por tales declaraciones falsas y si como resultado el proveedor de servicios de internet, confiando en tales declaraciones falsas, retiró o inhabilitó el acceso al material o actividad denunciados o en la sustitución del material retirado o dejó de inhabilitar el acceso a esta.

55 Almacenamiento en almacenamiento temporal del sistema, información que reside en los sistemas o redes en la dirección de los usuarios o herramientas de búsqueda de información. 
y muchos enlazan directamente a sus páginas los procedimientos de notificación y eliminación de la DMCA. Las víctimas también pueden emitir solicitudes de desindexación a los motores de búsqueda como Google, Yahoo!, Bing para eliminar enlaces infractores de los resultados de búsqueda.

Un problema que ocurre durante los procedimientos de eliminación es el llamado Whac-a-Mole, esto es que, al eliminar contenido infractor en un lugar, vuelve a "aparecer" en otro, que recuerda al juego de video Whac-a-Mole. ${ }^{56}$ En el caso de pornografía no consentida, este fenómeno se magnifica. Los portales de internet de pornografía no consentida están destinados a dañar la reputación y arruinar vidas. Los avisos de eliminación requieren la divulgación de información personal, por lo que las víctimas pueden atraer inadvertidamente más atención a la imagen, ya que los portales de internet podrían crear publicaciones adicionales sobre las víctimas que solicitan "descolgar" las imágenes con acceso al público. También, algunos de los usuarios pueden animar a otros a volver a publicar las imágenes de las víctimas en otros lugares en internet.

\section{Excepción contra la pornografía no consentida: responsabilidad secundaria: la responsabilidad secundaria ${ }^{57}$}

La doctrina de la infracción secundaria del derecho de autor norteamericano es una alternativa jurídica para adjudicar responsabilidad a los portales de internet (Yen, 2000) que lucran con el acto de publicar $^{58}$ imágenes de pornografía no consentida. ${ }^{59}$

56 Whac-A-Mole es un juego de arcade, o de mesa, que consiste en un área en donde hay cinco agujeros y en la parte superior del área de juego está lleno de pequeños topos de plástico que aparecen al azar. El objetivo es darle con unos mazos a los topos, pero cada vez que se le da en un agujero, vuelve a aparecer en otro lugar, así como las imágenes que se sacan de un portal de internet y vuelven a salir en otro lugar.

57 Cfr. Caitlin (2014); Oltermann (2014).

58 Schatts v. Curtis Manangement Group, 764 Fed.Supp. pags. 902 y 908. Ley de Derechos de Autor Federal, 90 Stat. 2541. Pub. L. 94-553 17 U.S.C. Sección 101.

59 Gucci Am., Inc. v. Hall \& Assocs., 135 F. Supp. 2d 409, 413 (S.D.N.Y. 2001); Parkerv. Google, Inc., 422 F. Supp. 2d 492, 502 n.8 (E.D. Pa. 2006); Ford Motor Co. v. GreatDomains.com, Inc., No. 00-CV-71544-DT, 2001 WL 1176319, p. 1 (E.D. Mich. Sept. 25, 2001) sobre la relación de la Sección 230 con el Derecho de Marcas, Federal Bank-Corp. v. Earthlink, Inc., 2005 WL 2240952 (W.D. Wis. Sept. 13, 2005), es el derecho de autor federal y no estatal, así lo decidió el caso de Perfect 10, Inc. v. CCBill, LLC, 488 F.3d 1102, 1119 (9th Cir. 2007); estipulado Curran v. Amazon.com, Inc., 2008 WL 472433 (S.D. W.Va. Feb. 19, 2008). Perfect 10, Inc. v. CCBill, LLC, 340 F. Supp. 2d 1077 (C.D. Cal. 2004); Carafano 
La ley de derecho de autor norteamericano no dispone específicamente sobre la infracción "secundaria", pero la jurisprudencia norteamericana reconoció y desarrolló la doctrina de infracción secundaria contributaria y vicaria.

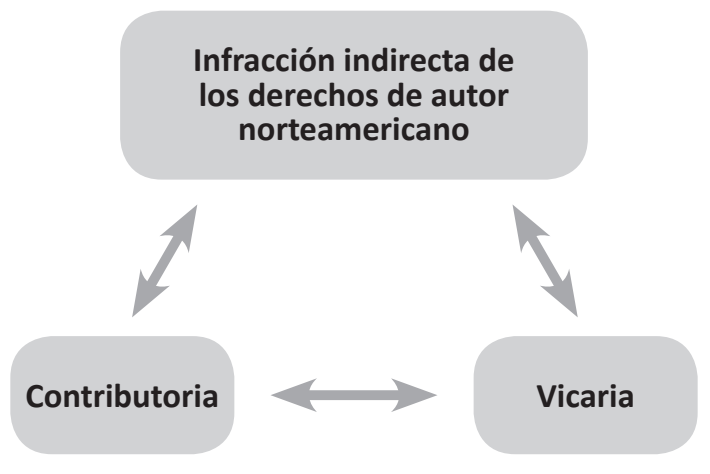

Figura 1. Infracción indirecta de los derechos de autor norteamericano.

Fuente: elaboración propia.

\subsection{Infracción secundaria en su vertiente contributoria ${ }^{60}$}

El Tribunal Supremo de EE. UU. (en adelante, TSEEUU) ratificó la responsabilidad secundaria contributaria de derechos de autor. ${ }^{61}$ Uno de los casos más

v. Metrosplash.Com, Inc., 339 F.3d 1119, 1125 (9th Cir. 2003). Sin embargo, en Doe v. Friendfinder Network, Inc., 540 F. Supp. 2d 288 (D.N.H. 2008) se siguió el dictum de Universal Commc'n Sys., Inc. v. Lycos, Inc., 478 F.3d 413 (1st Cir. 2007) y disintió "with the Ninth Circuit's decision in Perfect 10 that [section] 230(e)(2) exempts only federal intellectual property laws from the operation of [section] 230". La Corte de Friendfinder expresó, “[c]onsistent with its text, $\$ 230(\mathrm{e})(2)$ applies simply to 'any law pertaining to intellectual property’, not just federal law”. Veáse también Atlantic Recording Corp. v. Project Playlist, Inc., 603 F. Supp. 2d 690 (S.D.N.Y. 2009), en el cual se decidió que la Sección 230 no impedía que se aplicara la ley estatal de derechos de autor y la ley estatal de competencia desleal. En la página 703, la Corte expresó: "Congress specified whether it intended a subsection to apply to local, state, or federal law. It is therefore clear from the statute that if Congress wanted the phrase 'any law pertaining to intellectual property' to actually mean 'any federal law pertaining to intellectual property,' it knew how to make that clear, but chose not to".

60 Se origina con la Ley de Patentes, 35 USCA 271 (c). Para un recuento en detalle, véase la magnífica obra del Dr. Pedro G. Salazar (1999, pp. 259-264).

61 Perfect 10, Inc. v. Visa Int'l Service Ass'n, 494 F.3d 788, 795 (9th Cir. 2007) (citando a Ellison v. Robertson, 357 F.3d 1072, 1076 (9th Cir. 2004). 
citados en las últimas décadas es el caso conocido como Betamax. ${ }^{62}$ En el caso se argumentó que el fabricante y distribuidor de la videograbadora Betamax (Sony) fue responsable de la infracción indirecta a la ley de derechos de autor de EE. UU. Esta infracción se fundamentó en la infracción directa cometida por los consumidores que tenían una Betamax y grababan sin autorización programas de televisión en sus casas. El TSEEUU determinó que la responsabilidad contributaria está subsumida en el artículo 106 de la Ley de Derechos de Autor. Hemos discutido que el artículo le da al dueño de la obra el derecho exclusivo no solo para hacer copias, si no para "autorizar" a otros a hacer copias. La doctrina de responsabilidad contributaria del derecho de autor norteamericano se interpreta de manera parecida a la responsabilidad civil extracontractual en el derecho común. Los casos de responsabilidad civil extracontractual generalmente tratan a una persona que participa a sabiendas en un acto ilícito como solidariamente responsable con el autor del daño primario.

Tambien el TSEEUU, en el fallo de Batamax, incorporó una anterior definición de "contributory infringement": "[O]ne who, with knowledge of the infringing activity, induces, causes, or materially contributes to the infringing conduct of another, may be held liable as a 'contributory' infringer". ${ }^{63}$

El TSEEUU aplicó la excepción doctrinal del staple article de la ley de patentes norteamericana. ${ }^{64}$ Este caso implicó uno posterior que puede impactar a las víctimas de pornografía no consentida, que es la teoría del inducimiento, porque no hay autorización para hacer una copia, y mucho menos para hacer varias copias de una imagen que infringe la ley de derechos de autor.

\subsection{El caso del inducimiento Metro Goldwyn-Mayer Studios (MGM) inc. v. Grokster y Stream Cast Networks ${ }^{65}$}

En este caso, las demandadas Grokster y Stream Cast Networks distribuyeron un programa gratuito que permitió a sus usuarios intercambiar archivos electrónicos en forma directa desde sus computadores con conexión a internet sin la necesidad de pasar por un servidor central (Miles, 2004). Estas empresas no tenían conocimiento de cuándo un archivo en particular era copiado, pero aportaron las herramientas tecnológicas para hacerlo. El TSEEUU, en su fallo, impuso la

62 Sony Corp of America v. Universal City Studios, 464 US 417 (1984).

63 Gershwin Publ'g Corp. v. Columbia Artists Mgmt., Inc., 443 F.2d 1159, 1162 (2d Cir. 1971).

6435 U.S.C. $\$ 271$ (c).

65 Metro Goldwyn-Mayer Studios (MGM) inc. vs. Grokster y Stream Cast Networks. 
responsabilidad indirecta a los portales de internet, debido al alto número de descargas que infringían las leyes de derechos de autor norteamericano. El TSEEUU utilizó la "regla del inducimiento" (Oswald, 2006) para diferenciar este caso del caso Betamax. Concluyó que las partes demandadas Grokster y Stream Cast Networks activamente promocionaron y alentaron a sus usuarios a bajar archivos protegidos por la Ley de Derechos de Autor norteamericana. Para ello, se valieron de publicidad que no solo promovía el uso ilegal de los programas, sino también explicaba cómo hacerlo. El TSEEUU confirmó unas decisiones anteriores en cuanto a que se le asigna responsabilidad a aquel que induzca y promueva el uso de tecnología que tenga el efecto de violar los derechos de autor. Asimismo, afirmó que el objetivo ilegal de los productos de Grokster y Stream Cast Networks fue inequívoco, porque no intentaron desarrollar herramientas de filtración $\mathrm{u}$ otros mecanismos que pudiesen evitar, o al menos disminuir, las actividades ilegales de sus usuarios. Finalmente, concluyó que la teoría del inducimiento requiere evidencia de violaciones efectivas (Choi, 2005).

Ahora bien, traigamos esta teoría esbozada de responsabilidad indirecta "del inducimiento" de derechos de autor norteamericano ${ }^{66}$ a los casos de pornografía no consentida.

a. Hay un portal que, como myex.com, tiene la intención y la misión comercial de presentar imágenes que tienen derechos de autor de un tercero.

b. No hay filtración alguna que ayude a evitar el uso de imágenes de manera ilícita en estos portales de internet.

c. Todos estos portales ganan dinero por las imágenes vertidas en ellos, a sabiendas de que no tienen el permiso de uso y divulgación de las imágenes de las mujeres afectadas. Los portales se enriquecen de la venta de anuncios, ${ }^{67}$ por lo tanto, la teoría del inducimiento ${ }^{68}$ aplica a un portal que usa sin consentimiento

66 David v. CBS Interactive Inc., 2:11-cv-09437-DSF-JC (C.D. Cal. Feb. 19, 2013); Amaretto Ranch Breedables v. Ozimals Inc., 2012 WL 5389897 (N.D. Cal. November 5, 2012).

67 En un caso posterior, el Tribunal del Primer Cicuito de Apelaciones realizó una expresión muy pertinente "[regardless, w]e need not decide whether a claim premised on active inducement might be consistent with Section 230 in the absence of a specific exception. Even assuming that active inducement could negate Section 230 immunity, it is clear that UCS has not alleged any acts by Lycos that come even close to constituting the 'clear expression or other affirmative steps taken to foster' unlawful activity that would be necessary to find active inducement [...] The 'unmistakable' evidence of an 'unlawful objective' found in Grokster is entirely absent here” Universal Communications Systems v. Lycos, 478 F.3d 412 (2007).

68 El artículo 1202 es una disposición poco conocida de la DMCA que dispone que es ilegal retirar intencionalmente o alterar cualquier información sobre gestión de derechos de autor o de distribución de copias de obras en las que la información de derechos de autor ha sido 
imágenes de mujeres desnudas e induce mediante promoción o modelo de negocios electrónicos a que se usen estas imágenes para generar una ganancia.

Por lo que entendemos, es una alternativa para negar las protecciones de derechos de autor a las imágenes de pornografía no consentida.

\section{Infringir indirectamente el derecho de autor de forma vicaria}

Finalmente, existe la infracción de derecho de autor secundaria de la variante vicaria cuando la capacidad de supervisar se une a un interés financiero en la explotación ilegal de los derechos de autor, incluso en ausencia de conocimiento de la violación de los derechos de autor. La normativa de derechos de autor impone responsabilidad sobre el beneficiario de la explotación ${ }^{69}$ monetaria por la infracción de derecho de autor cuando la acción de infringir este derecho ocurre en sus predios o en alguna organización que controla. En el caso Bernstein (Bernstein and Co. v. H.L. Green Co, 1963), ${ }^{70}$ el Tribunal impuso la responsabilidad por infracción vicaria porque la empresa tiene un deber vicario de supervisión de lo que ocurre en sus predios. Esto quiere decir que una empresa será responsable por las infracciones a la ley de derecho de autor en su portal de internet. Quiere decir que si una persona utiliza un portal de internet para infringir los derechos de autor y este no corrige ni toma los pasos para evitar esta violación, entonces ese portal puede responder por infracción vicaria de derechos de autor. Estas doctrinas jurisprudenciales presentan una oportunidad para las víctimas de los actos de pornografía no consentida.

\section{Conclusión}

Sin lugar a dudas, la pornografía no consentida es un acto de violencia ejercida contra una persona.

En el ordenamiento norteamericano, existen alternativas en el derecho de propiedad intelectual específicamente en lo concerniente al derecho de autor.

Hemos presentados varias teorías jurídicas que avalan el uso del derecho de autor no solo contra la persona natural que hace los actos específicos de pornografía no consentida, sino también contra las empresas u organizaciones dueñas de los portales de internet que las distribuyen.

suprimida o alterada.

69 Shapiro, Bernstein \& Co. v. HL Verde Co., 316 F. 2d 304, 307 (2d Cir. 1963).

70 Supra. 


\section{Recomendaciones:}

a. Permitir que los derechos de autor de victimas de pornografía no consentida sean reconocidos e incluso registrados en la Oficina de Derechos de Autor de manera confidencial, sin costo y de forma expedita. Esto permitirá que las victimas puedan usar el sistema de aviso del DMCA y tratar de reducir la distribución ilegal de sus imágenes.

b. Enmendar el mínimo de cuantía que presenta la ley NET y su aplicación en caso de pornografía no consentida.

c. Enmendar la Ley de Derechos de Autor para incluir el inducimiento y la razón de ser del portal de internet como determinante para ofrecer las inmunidades del artículo 512 del DMCA y del artículo 230 de la CDA.

\section{Bibliografía}

Acevedo-Castillo, N., Laso-Samsing, C. y Norambuena-Avilés, R. (2020). Violencia sexual y acoso en la web: evidenciando la falta de tutela judicial efectiva. Entorno, (69), 81-89.

Ambale, M. (2008). Fair Housing Council of San Fernando Valley v. Roomates. com, LLC 521 F. 3d 1157 (9th Cir. 2008).

Brown, S. (1998). The No Electronic Theft Act: Stop Internet Piracy! DePaul Journal of Art, Technology \& Intellectual Property Law, 9(1), 147-164. https://via.library.depaul.edu/jatip/ vol9/iss 1/6.

Burris, A. (2014). Hell hath no fury like a woman porned: Revenge porn and the need for a federal nonconsensual pornography statute. Florida Law Review, 66, 2325-2399.

Caitlin, D. (8 de septiembre de 2014). How copyright became the best defense against revenge porn. The Washington Post. http://www.washingtonpost.com/news/the-intersect/ wp/2014/09/08/how-copyright-became-the-best-defense-against-revenge-porn/.

Cecil, A. L. (2014). Taking back the Internet: Imposing civil liability on interactive computer services in an attempt to provide an adequate remedy to victims of nonconsensual pornography. Washington and Lee Law Review, 71(4), 2513-2556.

Choi, B. H. (2005). The Grokster Dead-End. Harvard Journal of Law and Technology, 19, 393-412.

Citron, D. K. y Franks, M. A. (2014). Criminalizing revenge porn. Wake Forest Law Review, 49 , 345-391.

De Brea, P. V. (2015). La regulación de la pornografía no consentida en Argentina. Centro de Estudios de Libertad de Expresión y Acceso a la Información (CELE). Universidad de Palermo. Disponible en: https://www.palermo.edu/cele/pdf/Paper-regulacion-pornografia.pdf.

De Oliveira, L. C. O. y Taroco, L. S. Z. (2020). Pornografía de venganza, tecnologías y nuevos espacios para la violación. Derecho y Cambio Social, (61), 454-474.

Donner, I. (1992). The Copyright Clause of the US Constitution: Why Did the Framers Include It with Unanimous Approval? The American Journal of Legal History, 36(3), 361-378. 
End Violence Against Women. (2013). New Technology: Same Old Problems. https://www.endviolenceagainstwomen.org.uk/wp-content/uploads/Report_New_Technology_Same_Old_ Problems.pdf.

Expósito, F. y Moya, M. (2011). Violencia de género. Mente y cerebro, 48(1), 20-25.

Fenning, K. (1929). The Origin of the Patent and Copyright Clause of the Constitution. Journal of the Patent Office Society, 11, 438.

Franks, M. A. (2015). Drafting an effectivérevenge porn'law: A guide for legislators. http://dx.doi. org/10.2139/ssrn.2468823.

Franks, M. A. (2017). Revenge Porn Reform: A View from the Front Lines. Florida Law Review, 69, 1251-1337.

Goldman, E. (2003). A road to no warez: The No Electronic Theft Act and criminal copyright infringement. Oregon Law Review, 82, 369.

Goldstein, J. (29 de octubre de 2020). 'Revenge porn' was already commonplace. The pandemic has made things even worse. The Washington Post. https:/www.washingtonpost.com/lifestyle/style/ revenge-porn-nonconsensual-porn/2020/10/28/603b88f4-dbf1-11ea-b205-ff838e15a9a6_ story.html.

Hadwin, J. (2017). Victim blaming and third-person effect: A comparative analysis of attitudes for revenge porn and sexual assault (Tesis de Maestría). Oklahoma State University. https://hdl. handle.net/11244/54533.

Huber, A. (2020). Women, image based sexual abuse and the pursuit of justice (Disertación doctoral). Liverpool: John Moores University.

Jie, W. A. N. G. (2011). Philosophical Analysis of "Safe Harbor" Provision. Journal of Foshan University (Social Science Edition), (1), 3.

Kopf, S. (2013). Avenging revenge porn. Mod. Am., 9, 22.

LaMotte, S. (9 de septiembre de 2020). Así recopilan información de tus hijos pequeños a través de las apps. CNN. https://cnnespanol.cnn.com/2020/09/08/asi-recopilan-informacion-detus-hijos-pequenos-a-traves-de-las-apps/.

Lee, A. J. (2005). MGM Studios, Inc. v. Grokster, Ltd. y In re Aimster Litigation: A Study of Secondary Copyright Liability in the Peer-to-Peer Context. Berkeley Technology Law Journal, 20(2), 485-508.

Levendowski, A. (2013). Using copyright to combat revenge porn. Journal of intellectual property and entertainment law, 3, 422.

Lichter, S. (2013). Unwanted exposure: civil and criminal liability for revenge porn hosts and posters. Harvard Journal of Law \& Technology.

Luño, A. E. P. (1998). Internet y el Derecho. Informática y derecho: Revista iberoamericana de derecho informático, (19), 721-734.

Maddocks, S. (2018). From non-consensual pornography to image-based sexual abuse: Charting the course of a problem with many names. Australian Feminist Studies, 33(97), 345-361.

Maddocks, S. (2020). 'A Deepfake Porn Plot Intended to Silence Me': exploring continuities between pornographic and 'political'deep fakes. Porn Studies, 1-9.

Matsui, S. (2015). The criminalization of revenge porn in Japan. Washington International Law Journal, 24, 289.

McGlynn, C. y Rackley, E. (2017). More than 'Revenge Porn': image-based sexual abuse and the reform of Irish law. Irish Probation Journal, (14), 38-51. 
McGlynn, C., Johnson, K., Rackley, E., Henry, N., Gavey, N., Flynn, A. y Powell, A. (2020). 'It's Torture for the Soul': The Harms of Image-Based Sexual Abuse. Social \& Legal Studies. https://doi.org/10.1177/0964663920947791.

Miles, E. (2004). In re Aimster \& (and) MGM, Inc. v. Grokster, Ltd.: Peer-to-Peer and the Sony Doctrine. Berkeley Technology Law Journal, 19, 21.

Montero, E. (2000). La responsabilité des prestataires intermédiaires de l'Internet. Revue Ubiquité (5), 99-117.

Montero, E. (2001). La responsabilité des prestataires intermédiaires sur les résaux. Cahiers du Centre de Recherches Informatique et Droit (monográfico: Le commerce électronique européen sur les rails? Analyse et propositions de mise en œuvre de la directive sur le commerce électronique), (19), 273-295.

Morris, M. A. (2017). Empathy Induction to Reduce Victim Blaming in Revenge Porn Cases.

Musoni, M. (2019). The criminalization of "Revenge Porn" in South Africa. Obiter, 40(1), 61-74.

Oltermann, P. (2014). Revenge porn' victims receive boost from German court ruling. Koblenz court orders man to delete nude images of ex-partner, even though he had shown no intention of publishing them. The Guardian. http://www.theguardian.com/technology/2014/ may/22/revenge-porn-victims-boost-german-court-ruling.

Oswald, L. J. (2006). The intent element of inducement to infringe under patent law: Reflections on Grokster. Michigan Telecommunications and Technology Law Review, 13, 225.

Pedro, J. (1996). Desregulación y competencia en la Ley de Telecomunicaciones norteamericana de 1996. Revista de administración pública, (141), 337-376.

Plaza, J. (23 y 24 de abril de 2001). La responsabilidad civil en Internet: su regulación en el Derecho comunitario y su previsible incorporación al Derecho espańol. La Ley, (5293 y 5294).

Puente, S. N., Romero, D. F. y Cupeiro, S. V. (2015). El impacto de Internet como herramienta de lucha contra la violencia de género. Análisis de la brecha digital y de los procesos de victimización. Revista europea de derechos fundamentales, (26), 65-77.

Rico, M. N. (1996). Violencia de género: Un problema de derechos humanos. CEPAL. https:// repositorio.cepal.org//handle/11362/5855.

Rood, M. L. y Schriner, J. (2020). The Internet Never Forgets: Image-Based Sexual Abuse and the Workplace. En Handbook of Research on Cyberbullying and Online Harassment in the Workplace (pp. 107-128). IGI Global.

Salazar. P. G. (1999). La Protección Legal del Autor puertorriqueño (2ª ed.). Universidad De Puerto Rico.

Samuelson, P. (2006). Three Reactions to MGM v. Grokster. Michigan Telecommunications and Technology Law Review, 13, 177.

Schechter, R. E. y Thomas, J. R. (2003). Intellectual Property: The Law of Copyrights. Patents and Trademarks, 16(3).

Stroud, S. R. (2014). The dark side of the online self: A pragmatist critique of the growing plague of revenge porn. Journal of Mass Media Ethics, 29(3), 168-183.

Stroud, S. (24 de agosto de 2016). What Exactly is Revenge Porn or Nonconsensual Pornography? (Excerpt from "Social Media, Online Sharing, and the Ethical Complexity of Consent in Revenge Porn”). En Close Scheinbaum, A. (Ed.), Online Consumer Behavior: The Dark Side of Social Media. Routledge, Forthcoming. https://ssrn.com/abstract=2828740.

Tomeo, F. (2010). ¿¿Deben responder las redes sociales por contenidos publicados por terceros? 
En La Comunicación Social, en estado critico. Entre el mercado y la comunicación para la libertad: actas del II Congreso Internacional Latina de Comunicación Social. Tenerife: Sociedad Latina de Comunicación Social.

Uhl, C. A., Rhyner, K. J., Terrance, C. A. y Lugo, N. R. (2018). An examination of nonconsensual pornography websites. Feminism \& Psychology, 28(1), 50-68.

Vaina, L. (27 de junio de 2019). ¿Qué significan las siglas LGBTIQ+? La Vanguardia. https:// www.lavanguardia.com/vida/junior-report/20190627/463124839887/lgbtiq-definiciones. html.

Valenti, J. (1 de septiembre de 2014). What's Wrong With Checking Out Stolen Nude Photos of Celebrities The ethics of looking away. http://www.theatlantic.com/entertainment/archive/2014/09/leaked-photos-nude-celebrities-abuse/379434/.

Vega-Lozada, F. (2014). La Venganza Pornográfica (Revenge Porn) y la violencia de género perspectivas del ordenamiento jurídico norteamericano y puertorriqueño (pp. 53 -72). http:// fiadi.org/wp-content/uploads/2015/04/XVIII-Fiadi-CR-Lunes.pdf.

Walz, C. N. y Rogers, R. L. (III). (2013). Sixth Circuit's Decision in Jones v. Dirty World Entertainment Recordings LLC Repairs Damage to Communications Decency Act. Communications Lawyer, 30, 4.

Wang, J. (2018). Self-regulation of Copyright Enforcement on Hosting Platforms. En Regulating Hosting ISPs' Responsibilities for Copyright Infringement (pp. 199-227). Singapur: Springer.

Yen Alfred, C. (2006). Third-Party Copyright Liability After Grokster. Minnesota Law Review, $91,184$.

Yen, A. (2000). Internet Service Provider liability for subscriber copyright infringement, enterprise liability, and the First Amendment. The Georgetown Law Journal, 88, 1833-1893. 
